\title{
The Study of Recreations in A hundred Children at Play and Living Condition of Children in Song Dynasty: A Brief Discussion on The Nuo Dance of Children
}

\author{
Xia Hua \\ Jiangsu Open University, Nanjing 210000, China \\ 896722571@qq.com
}

Keywords: Children, Recreations, Nuo Dance, Living Condition, Status.

\begin{abstract}
This essay explains the connection between children's entertainment and the life, and the status of Children in Song dynasty. In contrast to some popular games, Nuo(傩, to exorcise evil spirits) dance is so uncommon that it could be associated with medical issues, the attitudes of the Government. Therefore, Nuo dance for children in the painting contains the auspicious implications, and it also shows that the government pays great attention to the education of children: these portrayals do not aim to show how children really amused themselves, but rather how they are being introduced into the adult world they have yet to participate in.
\end{abstract}

\section{Introduction}

Paintings on the theme of A Hundred Children at play seem to emerge as a new topic in the twelfth and thirteenth centuries in China, which were classified as genre painting. The one-hundred children theme lacks a typical example in pre-Song periods. Some people believe that it originates from a traditional object "hundred children tents" that turns up in Chinese literature several centuries before Song dynasty. In fact, "Hundred" represents a large amount of number, while "Children" is a metaphor for very tiny things. In addition, our culture could be explained as a display of a thriving large family and embody the ability of fertility. The theme itself, full of good fortune, seems to have been an unique theme of the twelfth and thirteenth centuries.

\section{The contents of A Hundred Children at play}

The anonymous artist who created the A Hundred Children at play is a fan-shaped album leaf. It is crowed with human figures engaged in playful activities, such as at least six groups musical accompaniments, acrobats, dancing, a boy with doll, a boy with a gigantic brush, and a dwarf carrying an elephant tusk. Although it is difficult to identify various images in the painting, it still motivates my interest. It reminds me of Su Hanchen (苏汉臣), a famous painter for depicting children at play, has couples of paintings relating to boys or girls with different games and dolls. His A Hundred Children Enjoying Spring shows that many children are taking part into different games. Some perform music on the zither, some fly kites on the playground. However, the difference between the two paintings is convincing: the anonymous artist pay more attention to role- playing elements. The most vital meaning in this A Hundred Children at play album is to enable children to engage in mimicking adult behaviors, for example, in the right corner, a boy with a monstrously mask accompanies by a musician. The mask provides us a possibility that might be a role-playing of exorcise.

\section{Nuo Dance}

\subsection{The children playing Nuo Dance in the painting}

In the right corner of the painting, six boys are constituted a group that five of the members surround the boy with a monstrously mask and a green long gown printed white pattern. One is after him, telling him to go ahead; a boy keeps a doll in his arms; in front of the monster is a 
musician who is ringing a gong; a boy in red cloth and a pair of red shoes is dancing with a parasol; at the head of the line, a boy with a huge hat is holding an object like a fan in his hand; the three boys, including the musician, the dancer and the one with a fan, are wearing fake beards.

\subsection{The identity of the children and the medical situation in Song period}

Su Hanchen's painting, entitled Five Auspicious Sign, shows similarity to the picture we have here. Five boys play Nuo Dance in the garden, they wear the masks and dance.[1] The part of A Hundred Children at play also occurs in the beautiful garden, which reveals the privileged, upper-class setting. Here are no rowdies or hoydens playing in street. These are well-behaved boys and girls of the best well-educated families spaced neatly about a large, rich environment. There is an artificial pond, complete with aquatic plants and an exuberant tree. In addition, the two prominent stones indicate that are a kind of vogue, even a mania in twelfth and thirteenth centuries. None of the children in the luxurious landscape looks malicious or aggressive. In the childhood they tend to imitate the adult activities, such as the costumes, the conspicuous make-up and false mustaches that enable them to be looked as adults, and in the future, some of the children in the painted scene might turn out to become scholars, painters, musicians and writers. Nuo Dance is popular during that period, the children might have seen the process performed by the adults in daily life and they are able to play it, which could reflect the concern about auspicious views and the efforts on health and medical system in the society.

From the painting, the children imitating the Nuo Dance with masks indicate that the Nuo rituals has been gained popularity in daily life, and the nature of role-playing become the children's entertainment. Nuo is an ancient ritual of exorcism, which has a very early origin. The ancients believed in the existence of ghosts and gods in the world. Those who unfortunately suffer from disease need to expel the evil spirit, or they would lose peace and happiness. Therefore, people discovered a special form of dance - Nuo, making people happy through music and dance. "To serve the deity should use songs and dances."[2] According to the record, in Southern Song times, the court shifted the Nuo ritual to a performance with playfulness: they askes six girls to play six divinities in the Lunar New Year's Eve.[3]

In the painted scene, the five boys are mimicking the adults who played Nuo ever. Due to their simple costumes, it is difficult to identify the exact role they played. The boy with a parasol makes up slant eyebrows, looking like a clown mask, who might play the evil that everyone hates. The monster mask might be the famous god who drives evil spirits, Zhongkui, because we might recognize him from his green costume. In Song period, the Nuo Dance was not merely limited in the aim of exorcising the evil spirits, it was prone to combine with the entertainment, the blessing ceremonial performances, the praying for good harvest, for health and for giving birth to child. It is worth noting the sixth boy with a doll in his arms. What role might him play in this line? Perhaps he played a role whose child caught a disease, so he needed to prey for his child through Nuo Dance. To some extent the Nuo Dance in the painting could reflect the other side of the society: there were a great number of ordinary people who still only depended on the power of devilry. Because under the heavy burden of taxes they could not afford medicine; in certain remote villages they did not have enough doctors.[4]However, we can see that the phenomenon people turned to witch doctors still exist, the government had endeavored to improve the medical work in Song dynasty, such as developing the methods for diagnosis and treatment of disease, disseminating medical knowledge, and so forth.[5] It had a positive impact on promoting the physical conditions.

\section{Summary}

In the Song dynasty the paintings of children at play became popular. Upper-class boys and few girls were portrayed as inhabitants of a luxurious but highly domesticated landscape. Games were fun for children, but a closer observation shows that, these portrayals do not aim to show how children really amused themselves, but rather how they are being introduced into the adult world they have yet to participate in. Children's games, such as playing with dolls, playing as a guest, and so on, are theatrical performances for adult activities. They are shown at play, unconsciously becoming ideal grownups. Furthermore, Nuo Dance clearly shows that the children was associated 
with good luck and auspiciousness in Song dynasty. Meanwhile, the Nuo Dance we have seen here also provides us with the medical situation and living condition during that period.

\section{Acknowledgement}

This research was financially supported by Jiangsu Overseas Research \& Training Fellowship for Prominent Young \& Middle-aged Teachers and Presidents, 2015

\section{References}

[1] Wang Zhaoqian, Su Hanchen's Children at play and Nuo Dance Five Stars, Art of Huangmei Opera, vol.3, pp.4-7, 2002.

[2] Wang Guowei, The research of Song and Yuan drama, Taibei: The Commercial Press, Ltd, pp.3-4, 1981.

[3] Chen Hong, Wang Kui, The playfulness of Nuo Dance, Journal of East China Institute of Technology(Social Sciences), vol.03, pp. 256-259, 2003

[4] Li XIaohong, The discuss about "believing the power of devilry rather than professional doctors" in Song dynasty, The Sichuan University Journal (Philosophy and Social Sciences Edition ) vol.06, pp. 94-99, 2003

[5] Yao Haiying, the study of Medical activities and folk medicine groups in Song Dynasty through Yi Jianzhi, Guizhou Historical Studies, vol.01, pp. 47-51, 2011. 